\title{
Application Running Text Information Berbasis Android
}

\author{
Ferry Putrawansyah \\ Sekolah Tinggi Teknologi Pagar Alam; Jl. Masik Siagim No.75 Simpang Mbacang Kec. Dempo \\ Tengah Kota Pagar Alam \\ Program Studi Teknik Informatika \\ e-mail: *feyputrawansyah@gmail.com
}

\begin{abstract}
Abstrak
Tujuan penelitian ini adalah untuk mengembangkan Running Text diatur menggunakan android sebagai pengigat waktu adzan, sholat dan petugas khotbah pada hari jumat yang sering mengalami perubahan secara berkala. Masalah dalam penelitian ini yaitu Masjid Sekolah Tinggi Teknologi Pagaralam masih menggunakan jam dinding konvensional untuk pengaturan waktu sholat dan adzan dan pemberian petugas jumat yang masih menggunakan media papan tulis sehingga mempersulit marbot untuk mengganti jadwal secara berkala. Metode pengembangan sistem yang digunakan dalam penelitian ini yaitu metode rapid application development (RAD). Adapun tahap yang digunakan yaitu requirement planning, design workshop, build the system dan implementation. Untuk memperoleh data dalam penelitian ini, dilakukan teknik pengumpulan data diantaranya observasi, wawancara dan studi pustaka. Perangkat yang digunakan diantaranya smartphone, controller jam waktu sholat atmega328, Bluetooth HC-05, GPS, papan LED matrix P10 16x32, buzzer. Hasil dari application running text information berbasis android ini meemudahkan marbot mensinkronkan waktu sholat dan petugas jumat yang telah ditetapkan oleh Departemen Agama Kota Pagar Alam menggunakan Handphone Android..
\end{abstract}

Kata kunci: arduino uno, atmega 328, android

\begin{abstract}
The purpose of this study is to develop Running Text regulated using Android as a prayer time prayer, prayer and sermon on Friday which often changes regularly. The problem in this study is that the Pagaralam High School Technology Mosque still uses conventional wall clocks for prayer and adhan time settings and the provision of Friday officers who still use blackboard media makes it difficult for Marbot to change schedules regularly. The system development method used in this study is the rapid application development (RAD) method. The stages used are requirements planning, design workshops, build the system and implementation. To obtain data in this study, data collection techniques were carried out including observation, interviews and literature study. The devices used include smartphones, atmega328 prayer time controller clock, Bluetooth HC-05, GPS, P10 16x32 LED matrix board, buzzer. The results of this Android-based application running text information make it easier for Marbot to synchronize prayer times and Friday officers set by the Department of Religion of the City of PagarAlam using an Android mobile phone.
\end{abstract}

Keywords: arduino uni, atmega328, android 


\section{PENDAHULUAN}

Teknologi Informasi saat ini telah berkembang dengan pesat dan merevolusi cara hidup. Dengan demikian era informasi selalu member ruang lingkup yang sangat besar untuk membangun segala informasi melalui cara baru yang inovatif, dan memberikan kenyamanan dalam kehidupan sehari-hari. Dengan adanya Teknologi Informasi, kinerja dan proses suatu pekerjaan meningkat lebih cepat dibandingkan dengan sebelum adanya Teknologi Informasi yang disebarkan dengan bantuan teknologi secara digital.

Seiring perkembangan teknologi, munculah sebuah Teknologi Informasi berupa running text, yang berguna untuk mempermudah pengguna dalam mendapatkan informasi. Running text tersebut yaitu hasil dari pengkolaborasian antara lighting emitting diode (LED) dan Chip mikrokontroler yang merupakan sebuah kemajuan dalam perkembangan teknologi yang dapat dimanfaatkan dalam kehidupan manusia [1]. Salah satu contoh objek peneitian pada masjid STT Pagar Alam adalah Proses penyebaran informasi pada umumnya digunakan papan tulis atau spanduk, infomasi tersebut harus diubah secara berkala, baik informasi jadwal sholat, petugas sholat jumat sampai dengan informasi kegiatan, hal tersebut tentunya membutuhkan biaya secara berkala maka dengan adanya running text yang di letakan di masjid akan lebih efektif dan efisien dan juga sangat cepat dalam penyebaran informasi berkalanya.

Running text ini akan dikolaborasikan dengan mikrokontroler yang merupakan suatu alat elektronika digital yang mempunyai masukan dan keluaran serta kendali dengan program yang bisa ditulis dan dihapus dengan cara khusus, cara kerja mikrokontroler sebenarnya membaca dan menulis data [2], kemudian kebutuhan alat yag lain yaitu Atmeega28 dimana menjadi otak papan pada Arduino Uno, Komponen ini adalah sebuah Integreted Circuit (IC), yang dipasang ke header socket sehingga memungkinkan untuk dilepas. Chip ATmega328 memiliki banyak fasilitas dan kemewahan untuk sebuah chip mikrokontroler [3]. Chip tersebut memiliki 23 jalur general purpose I/O (input/output), 32 buah register, 3 buah timer/counter dengan mode perbandingan, interupt internal dan external, serial programmable USART, 2 wire interface serial, serial port SPI, 6 buah channel 10-bit A/D converter, programmable watchdog timer dengan os cilator internal, dan lima power saving mode. Chip bekerja pada tegangan antara $1.8 \mathrm{~V} \sim 5.5 \mathrm{~V}$. Output komputasi bias mencapai 1 MIPS per Mhz. Maximum operating frequency adalah $20 \mathrm{Mhz}$. ATmega328 menjadi cukup popular setelah chip ini dipergunakan dalam board Arduino. Dengan adanya Arduino yang didukung oleh software Arduino IDE, pemrograman chip ATmega328 menjadi jauh lebih sederhana dan mudah. [4], kemudian dibutuhkan buzzer sebagai pemancar load speaker, modul bluetooth HC-05 yang serial wireeless dengan gelombang radio frekuensi 2.GHz. [5]

\section{METODE PENELITIAN}

\subsection{Rancangan Flowchart Aplikasi}

Pada rancangan flowchart dibawah ini, menjelaskan bahwa ketika admin membuka aplikasi running text akan menampilkan menu utama berupa menu edit nama, running text setup, Bluetooth, iqomah, GPS, dan tanggal dan jam. Namun menu tersebut tidak dapat digunakan untuk update informasi pada papan LED matriks dikarenakan Bluetooth belum terkoneksi. Untuk masuk ke beberapa menu tersebut admin harus menghubungkan Bluetooth android dengan Bluetooth papan LED matriks, apabila Bluetooth belum terkoneksi maka admin kembali ke pencarian Bluetooth, apabila sudah terkoneksi, maka admin langsung menuju ke menu utama untuk melakukan pengaturan edit running text setup untuk mengatur kalimat atau teks berjalan pada papan $L E D$ matriks, pengaturan iqomah untuk mengatur waktu adzan dan waktu pelaksanaan sholat. 


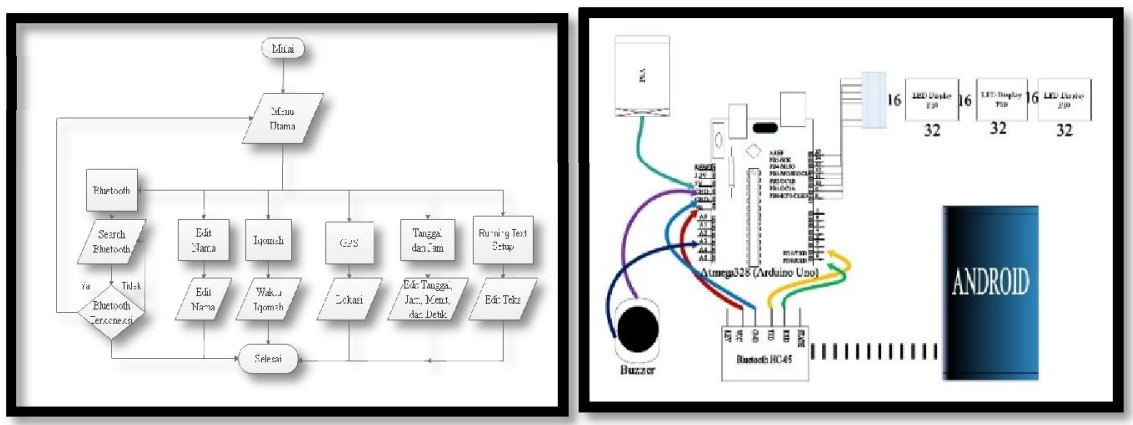

Gambar1. Rancangan Flowchart Aplikasi

\subsection{Spesifikasi Sistem}

Dalam perancangan application running text information berbasis android yang menggunakan mikrokontroler Atmega328 sebagai komponen utama yang mengatur komponen lainnya seperti: modul bluetooth HC-05, GPS yang sudah tersedia didalam controller Atmega328, LED display P10dan power supply dirancang agar controller Atmega328 dapat menerima masukan dari bluetooth, kemudian diproses sehingga hasil masukan dari bluetooth dapat ditampilkan oleh papan LED display P10.[5]

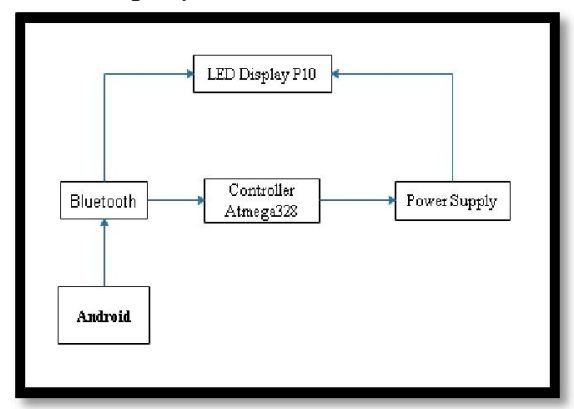

Gambar2. Block Diagram

\subsection{Class Diagram}

Pada class diagram gambar 3 dibawah ini menunjukan database server berelasi dengan menu utama. Dimana menu utama akan menunjukkan/menampilkan menu edit nama, Bluetooth, running text setup, iqomah, GPS, tanggal dan jam. Pada bagian menu utama berelasi dengan menu edit nama, menu iqomah, menu running text setup, menu GPS, Bluetooth, menu tanggal dan jam.

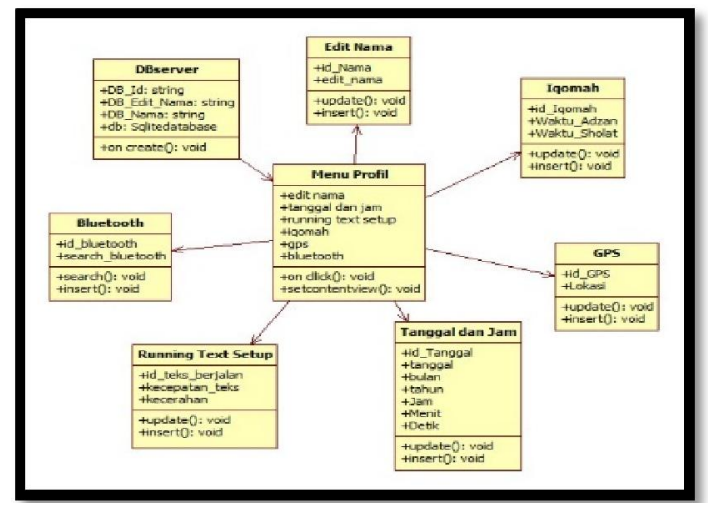

Gambar 3. Class Diagram 


\subsection{Activity Diagram}

Pada rancangan activity diagram pada gambar 4 dibawah ini menjelaskan bahwa admin ketika membuka aplikasi running text, maka aplikasi tersebut akan menampilkan menu utama, pada menu utama terdapat menu edit nama, menu iqomah, Bluetooth, menu Running Text setup, menu GPS, dan menu tanggal dan jam, setiap kali admin membuka menu yang terdapat pada aplikasi tersebut maka aplikasi akan menampilkan setiap menu yang dibuka kemudian papan LED menamplkan hasil yang sudah diperbarui setelah itu admin keluar untuk mengakhiri aplikasi tersebut.

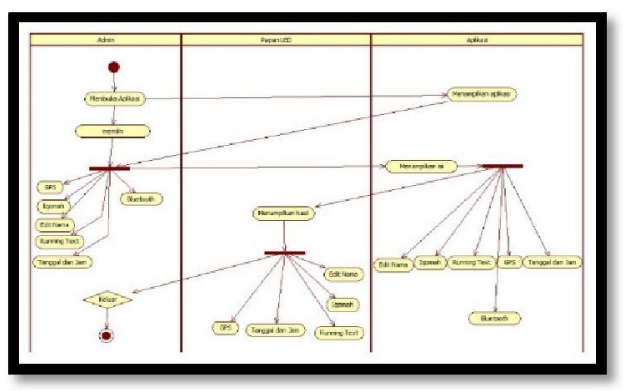

Gambar 4. Rancangan Activity Diagram

\section{HASIL DAN PEMBAHASAN}

Penelitian ini telah menghasilkan sebuah Teknologi Informasi berupa application running text information berbasis android sebagai waktu sholat dengan memanfaatkan jaringan Bluetooth dalam penyetingan aplikasi tersebut. Application running text information berbasis android ini akan diletakkan di Masjid Sekolah Tinggi Teknologi Pagaralam, admin menggunakan aplikasi android untuk mempermudah dalam penyetingan dalam penyebaran informasi. Didalam aplikasi android tersebut terdapat beberapa pengaturan diantaranya edit nama, GPS, running text setup, tanggal dan jam, koreksi waktu sholat, dan iqomah. Edit nama digunakan untuk mengatur nama Masjid atau tempat lokasi dimana application running text information berbasis android tersebut dipasang [3]. GPS digunakan untuk mengatur secara otomatis lokasi keberadaan yang sedang ditempati, running text setup digunakan untuk mengatur tulisan atau teks berjalan pada papan LED P10, tanggal dan jam digunakan untuk mengatur tanggal, bulan dan tahun serta jam pada papan LED P10. Koreksi waktu sholat digunakan untuk menambah atau mengurangi waktu sholat yang tidak sesuai, iqomah berfungsi untuk member peringatan berupa suara buzzer ketika akan dilakukannya adzan maupun sebagai pengingat batas waktu sholat sunahs etelah adzan

\subsection{Tampilan Menu Aplikasi}

Pada tampilan menu aplikasi pada gambar 5 dibawah ini terdapat beberapa aplikasi, namun dalam penyetingan application running text information berbasis android admin memilih aplikasi VIP Controller untuk dapat mengatur waktu sholat didalam Controller Atmega328. 


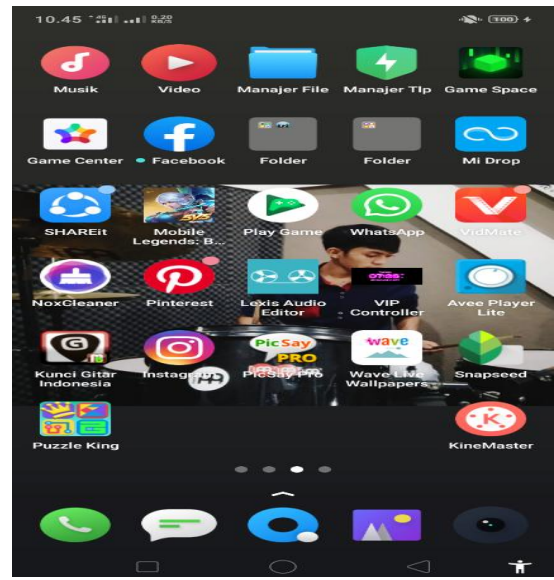

Gambar 5. Tampilan Menu Aplikasi

\subsection{Tampilan Search Bluetooth}

Pada tampilan search Bluetooth pada gambar 6 dibawah in adalah contoh Bluetooth yang terlihat oleh aplikasi android, pada tampilan tersebut terdapat nama Bluetooth BT04-A, dimana nama Bluetooth BT04-A adalah Bluetooth yang dipasangkan ke controller Atmega328. Untuk dapat melanjutkan kepenyetingan selanjutnya, admin harus memilih Bluetooth BT04-A agar aplikasi dapat terkoneksi dengan controller Atmega328.

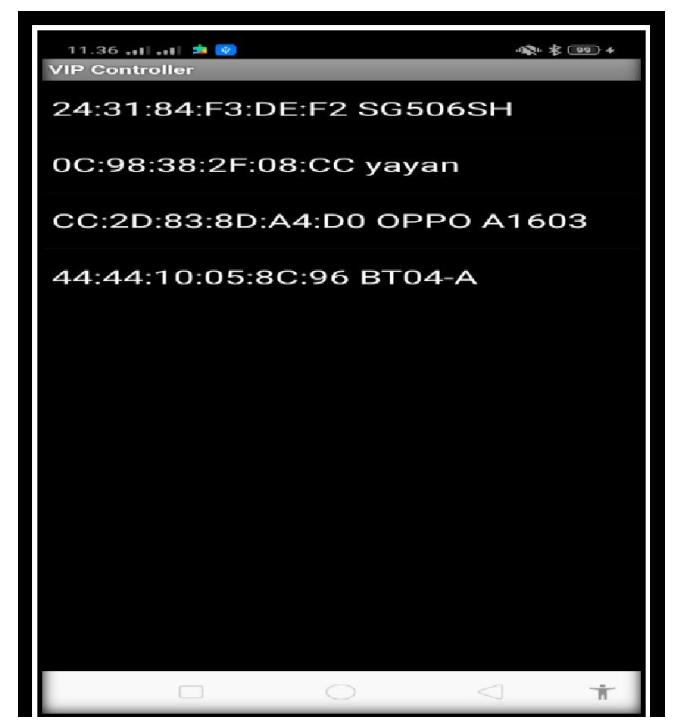

Gambar 6. Search Bluetooth

\subsection{Tampilan Menu Edit Nama, Tanggal \& Jam}

Pada tampilan edit Nama, Tanggal\& Jam pada gambar 7 dibawah ini merupakan tampilan penyetingan nama Masjid atau tempat lokasi Masjid pada papan LED display P10. Sedangkan tampilan penyetingan tanggal dan jam bermaksud untuk menyeting waktu sholat pada papan $L E D$ P10. Tombol Se tbermaksud untuk mengirim pesan yang sudah diedit, [2] 


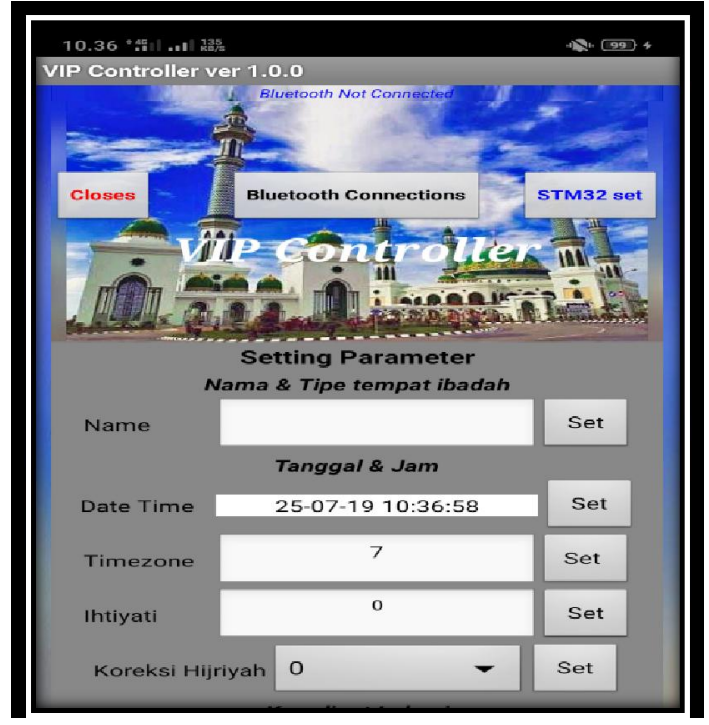

Gambar 7. Tampilan Menu Edit Nama, Tanggal dan Jam

\subsection{Tampilan Menu GPS dan Koreksi Waktu Sholat}

Pada tampilan GPS dan koreksi waktu sholat pada gambar 8 dibawah ini berfungsi untuk menyeting lokasi secara otomatis pada papan $L E D$, sedangkan koreksi waktu sholat digunakan untuk menambah atau mengurangi waktu yang tidak sesuai pada application running text information berbasis android. [6]

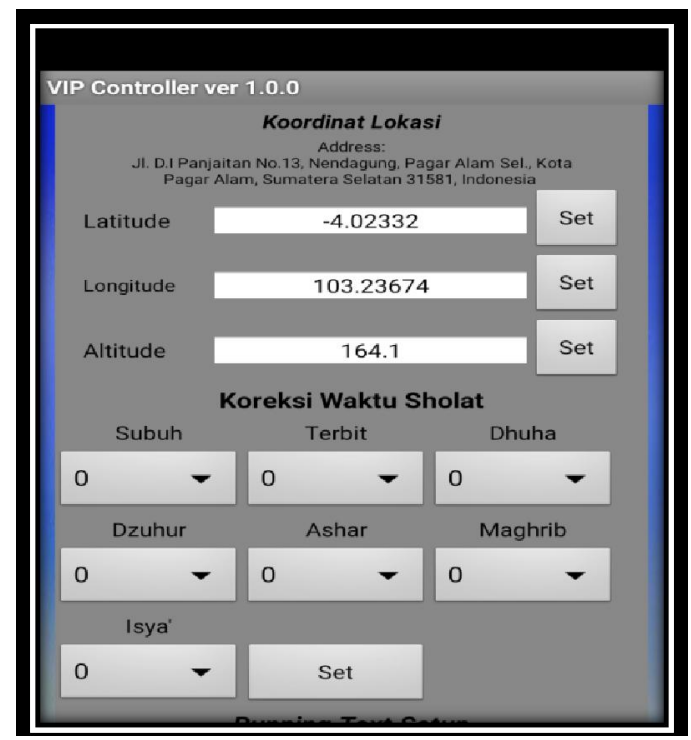

Gambar 8. Tampilan GPS dan Koreksi Waktu Sholat

\subsection{Tampilan Menu Running Text Setup}

Pada tampilan menu running text setup pada ambar 9 dibawah ini berfungsi untuk mengatur teks berjalan pada papan LED P10. Jika papan LED P10 lebih dari 3 buah, maka penyetingannya pun menggunakanNew Software running text 4-10 papan LED P10 [2] 


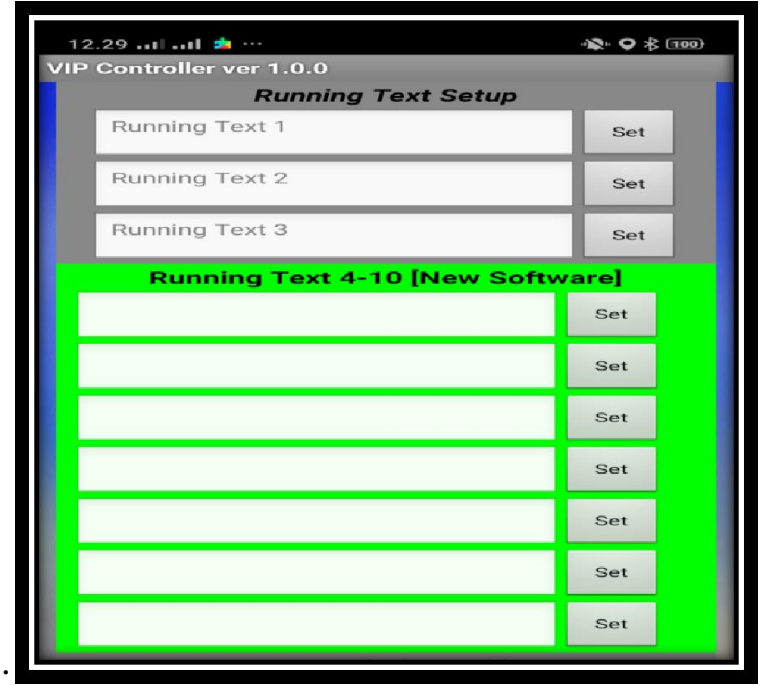

Gambar 9. Tampilan Menu Running Text Setup

\subsection{Tampilan Menu Pesan, KecepatandanIqomah}

Pada tampilan menu pesan pada gambar 10 dibawah ini berguna untuk menampilan pesan setelah adzan sholat wajib maupun sholat jum'at, sedangkank ecepatan berfungsi untuk mengatur gerak teks lambat atau cepatnya teks pada papan $L E D$ P10, dan iqomah digunakan untuk mengatur alarm berupa bunyi buzzer pada controller Atmega328 ketika akan dikumandangkannya sebuah adzan pada sholat wajib. [4]

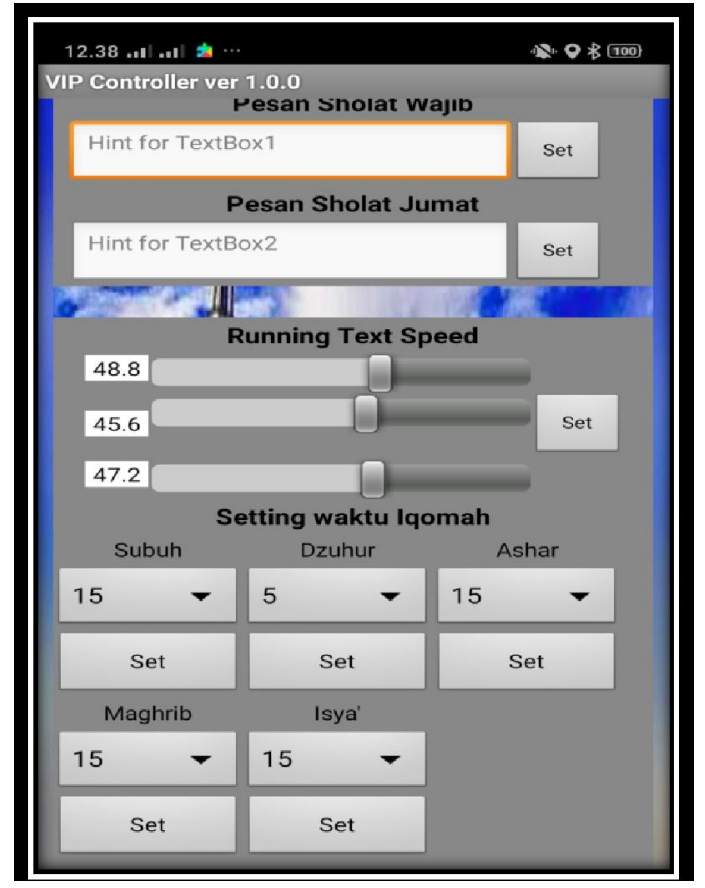

Gambar 10. Tampilan Pesan, Kecepatan dan Iqomah 


\subsection{Tampilan Menu Waktu Tunggu dan Kecerahan}

Pada tampilan menu waktu tunggu pada gambar 11 dibawah ini berfungsi untuk mengatur batas waktu sholat sunah setelah adzan dikumadangkan, sedangkan kecerahan berfungsi untuk mengatur kecerahan pada papan LED P10. [6]

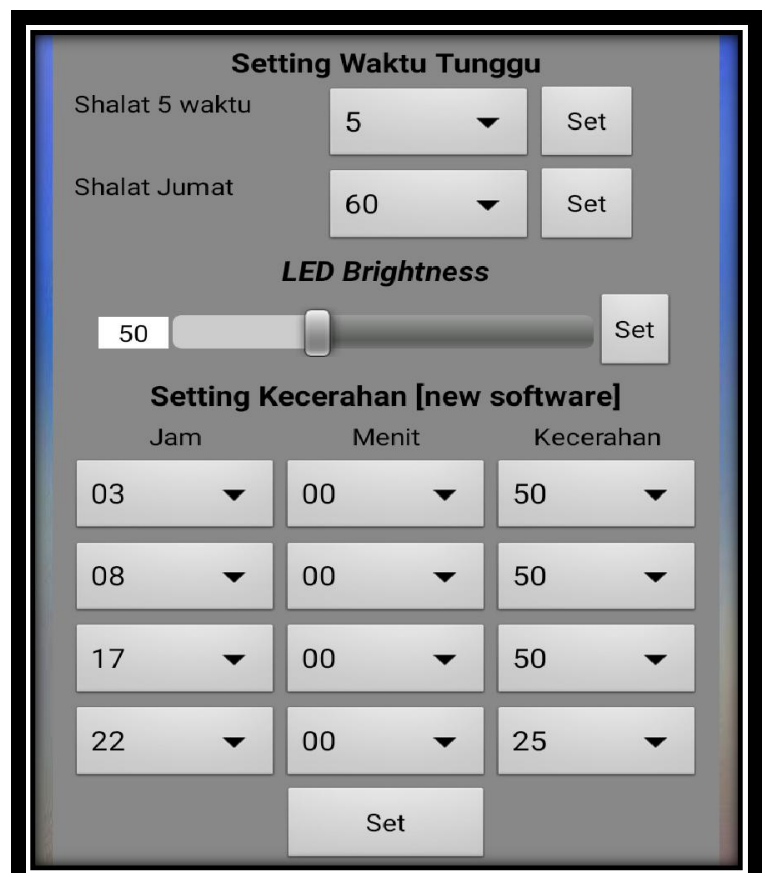

Gambar 11. Tampilan Menu WaktuTunggu dan Kecerahan

\subsection{Pengujian Pesan Running Text}

Sebelum Alat diimplementasikan maka diperlukan uji coba yang disesuaian dengan metode penembangan sistem yang digunakan dalam penelitian ini yaitu pengujian pesan dan pengujian jarak bluetooth yang dapat dilihat pada tabel 1 dan 2 berikut ini:

Tabel 1. Pengujian Pesan Running Text

\begin{tabular}{cccc}
\hline PengujianPesan & BanyaknyaPesanterkirim & BanyaknyaPesanGagal & Keterangan \\
\hline Pengujian Ke-1 & 2 & 0 & Berhasil \\
\hline Pengujian Ke-2 & 3 & 0 & Berhasil \\
\hline Pengujian Ke-3 & 5 & 0 & Berhasil \\
\hline
\end{tabular}

Tabel 2. Pengujian Jarak Bluetooth

\begin{tabular}{cccl}
\hline PengujianKe- & Percobaan & JarakBluetooth & \multicolumn{1}{c}{ Status } \\
\hline 1 & $2 \mathrm{Kali}$ & $3 \mathrm{Meter}$ & Bluetooth Terdeteksi \\
\hline 2 & $2 \mathrm{Kali}$ & $5 \mathrm{Meter}$ & Bluetooth Terdeteksi \\
\hline 3 & $2 \mathrm{Kali}$ & $6 \mathrm{Meter}$ & Bluetooth Terdeteksi \\
\hline 4 & $2 \mathrm{Kali}$ & $7 \mathrm{Meter}$ & Bluetooth Terdeteksi \\
\hline 5 & $2 \mathrm{Kali}$ & $10 \mathrm{Meter}$ & BluetoothTerdeteksi \\
\hline 6 & $2 \mathrm{Kali}$ & $15 \mathrm{Meter}$ & BluetoothTidakTerdeteksi \\
\hline
\end{tabular}




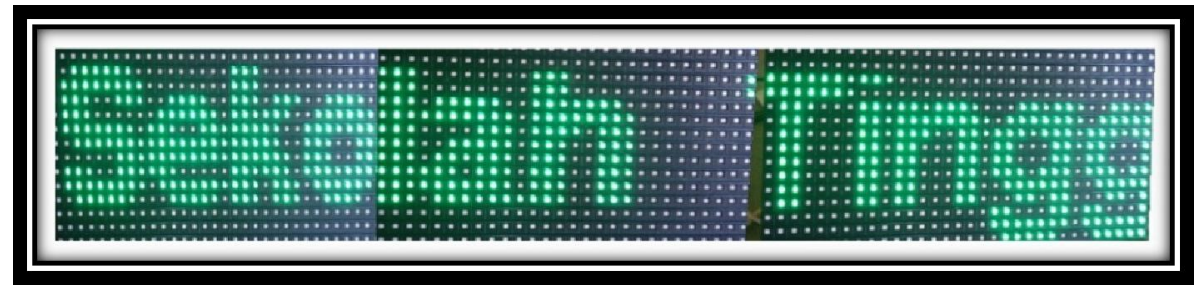

Gambar 12. Hasil Running Text

\section{KESIMPULAN}

Dari hasil pengujian yang telah dilakukan dalam implementasi Application Running Text Information Berbasis Android di Masjid Sekolah Tinggi Teknologi Pagaralam dapat diambil beberapa kesimpulan bahwa Connect Bluetooth dapat terdeteksi hingga jarak 7 meter., lamanya buzzer menyala rata-rata selama 10 Second dan dalam penyetingan running text hanya menggunakan aplikasi android.

\section{SARAN}

Saran untuk penelitian selanjutnya sebaiknya menggunakan modul GSM sehingga pada saat pengaturan pada Running Text dapat diatur pada saat kita diluar kota sekalipun.

\section{UCAPAN TERIMA KASIH}

Penulis mengucapkan terima kasih kepada Ibu Desi Puspita, M.Kom sebagai Kepala LPPM yang telah memberikan dukungan baik pikiran dan financial atas keberhasilan dalam penelitian ini sehingga baik tulisan dan alat dapat digunakan dengan baik

\section{DAFTAR PUSTAKA}

[1] E. S. Yanolanda Suzantry Handayani. 2018, Papan Informasi Digital Berbasis Arduino dan Android di Laboratorium Hardware Universitas Dehasen Bengkulu, Jurnal Teknologi Elektro, Universitas Mencu Buana, pp. 10-15.

[2] J. H. Rozali Toyib. 2016, Aplikasi Remote Kontrol CPU/Laptop Jarak Jauh Dengan Media Serial Handphone Dengan Mikrokontoller, Jurnal Pseucode, pp. 50-60.

[3] G. E. N. W. P. R. W. G. S. N. P. R. Yang Nadia Miranti. 2017, Pengembangan Pembelajaran HSK 3 dengan Menggunakan Perangkat Bergerak Berbasis Android," Jurnal Cakrawala Mandarin Asosiasi Program Studi Mandarin Indonesia, pp. 23-39.

[4] R. D. R. d. L. Arianto. 2015, Rancag Bangun Sistem Pengendalian Listrik Ruangan Dengan Menggunakan ATMEGA 328 dan SMS Gateway Sebagai Media Informasi, Jurnal Sistem Informasi, Teknologi Informatika dan Komputer. 
[5] N. K. Joko Christian. 2013, Prototipe Sistem Pendeteksi Kebocoran Gas LPG Menggunakan Sensor Gas MQ2, Board Arduino Duemilanove, Buzzer, dan Arduino GSM Shield pada PT. Alfa Retailindo ( Carrefour Pasar Minggu ), Jurnal TICOM, pp. 58-64.

[6] A. R. M. R. Irfanhady Hartatio Hermono. 2015, Security Car System Based GPS and SMS, e-Proceeding of Applied Science, pp. 2613-2623. 